\title{
For the Acquisition of Customers' Emotional Elements in the Service Design by SOMC: Simultaneous Observation Method based on Cooperation
}

\author{
Mi Young Seo, Eun Jong Lee \\ Department of Culture and Media Design, Handong Global University, Pohang, 791-780
}

\begin{abstract}
Objective: This research proposes a methodology, which validates a grasp of the customers' emotions in the service design area. Background: As the era of service design has taken its approach, the need for a deliberate design that would reflect the customer's experience had emerged in the area of service. Therefore, a variety of methodologies has been adopted in the field of service design with the purpose of discovery of the customers' needs. Even though the importance of an emotion-sentient research of a service experience increases, its research progress remains to be inadequate in comparison to all the other areas. Method: Having had taken some resources from the emotional studies under other areas of expertise as a base, the concept of volatility of emotions has been introduced as the core element of this research, further followed by an elaboration of its special characteristics. The observation technique under Stakeholder's system: SOMC(Simultaneous Observation Method based on Cooperation) has been proposed in this study as it presents an effective way to grasp the concept of volatile emotions in contrast to the previously existent types of methodologies. Results: The SOMC rather supplements the existing research methods than substitutes the previous ones. In other words, although the existing research system allowed emotion detection, it was difficult to capture the change of momentary and fickle emotions. On the opposite, the SOMC provides a condition allowing a sufficient grasp of the customer's emotions and facilitates emotional capture. Conclusion: For that reason, it is hoped that this piece of research represents a valuable and effective approach in terms of grasping the true needs of the customers on the emotional level, which will in its turn contribute to the improvement of the service quality in the midst of a complicated service condition. Application: Moreover, the purpose of this research is that in its outcome it may serve as a sufficient contribution to the area of emotional studies within the field of service design.
\end{abstract}

Keywords: Service design method, Volatile emotion

\section{Introduction}

가치이동의 개념에 따라 제조 기업들이 서비스기업화 되 어가고 있으며 제품이 서비스를 가능하게 하는 수단으로써 제품과 융합된 서비스가 개발되고 있다. 이에 따라 서비스 디자인 분야에서도 고객 경험의 중요성이 부각되고 있다.
왜냐하면 서비스는 경험해보지 않으면 가치를 느낄 수 없는 '경험재'이기 때문이다. 그렇기 때문에 고객이 원하는 경험의 니즈를 찾기 위한 다양한 방법론들이 경험 디자인 분야와 서 비스 디자인 분야에서 구분 없이 광범위하게 사용되고 있다.

지금까지 고객의 니즈를 발견하기 위해 다양한 방법론들 을 사용해 왔지만 미묘한 고객의 감성 변화를 포착하기는 쉽지 않았다. 대부분의 기존 방법론은 리서치 진행 후 고객 
의 감성 변화에 대한 질문을 하게 되는데 고객은 각 단계에 서의 세부적인 감정에 대해 요약(summarization)하여 말하 거나 감성 변화가 있던 시점을 기억해 내는데 어려움을 가진 다. 그러므로 각 단계에서 순간적인 감성 변화를 즉시 파악 할 수 있는 새로운 방법론이 필요하다. 이와 더불어 서비스 디자인 방법론이 가진 단점은 보완하고 장점은 결합하여 활 용할 수 있는 방법론을 연구하도록 한다. 기존의 방법론들은 유용한 부분이 많지만 방법론에 따라 리서치 실행 단계에서 시간이 많이 걸리거나 리서치 분석 과정을 따로 들어야 한다. 또한 리서치 실행 준비를 하고 리서치 현장에 나갔을 때 예 상치 못한 변수에 적절히 반응하지 못한다. 대부분의 경우 다양한 관점으로 고객 니즈를 파악하기 위해 여러 차례 리 서치를 실행하다 보니 제반 비용과 시간 측면에서 많은 자 원이 들어간다. 따라서 리서치 단계를 줄이면서 최소한의 자 원으로 최대의 효과를 누리고, 다양하게 변하는 리서치 현장 에서 유연하게 대처할 수 있는 새로운 서비스 디자인 방법론 이 필요하다고 보았다.

본 연구에서 새로운 서비스 디자인의 감성 추출 방법론 필 요성을 설명하기 위하여 기존의 서비스 디자인의 조사 방법 론을 비교 분석하여 문제점을 파악한다. 그 후 고객 니즈 추 출의 한계점을 밝히고 선행 방법론들이 놓치고 있는 감성의 핵심 요소인 휘발성이 있는 감성에 대해 정의한다. 이를 바 탕으로 서비스 디자인에서 휘발적인 고객감성을 포착하기 에 유용한 Simultaneous Observation Method based on Cooperation(이하 SOMC) 방법론을 설명하고 주요특징 및 프로세스를 규명한다. 그 후 결론을 통해 고려사항 및 향후 연구과제에 대해 고찰해 본다.

\section{Limitations and Understanding of Service Design}

모든 산업 및 공공 분야에서 혁신수단으로써 서비스의 가 치가 증대하고 있으며 서비스 분야에 IT 및 네트워크 기술 이 적극적으로 도입되면서 서비스 산업은 양적 질적으로 크 게 성장함과 동시에 그 중요성과 복잡성은 더욱 증가하고 있 다. 이러한 일련의 변화는 서비스 혁신을 위한 새로운 방법 과 분야에 대한 요구로 이어졌다. 고객들은 서비스를 통해 총체적이면서도 통합적이되 그들의 감성이 배려됐을 뿐 아 니라 서비스-제품과의 세부적인 인터랙션까지 세심하게 배 려된 서비스를 경험하는 것을 원하게 되었으며 바로 이러한 시대적 요구에 부응하여 태동된 것이 서비스 디자인 분야다.

\subsection{The definition of service design}

현재까지 서비스 디자인 흐름의 방향을 담당하고 있는 주 요 서비스 디자인 선도 기업과 기관에서도 다양한 정의가 내려지고 있지만 그 정의가 관념적이라 정확한 전달이 어렵 다. 그에 비해 기존의 주요 정의들을 분석하여 서비스 디자 인의 대상과 목적, 결과물의 타겟, 도출 방법, 프로세스, 결 과물의 특성, 결과물의 형태, 아이덴티티(Identity)의 프레 임워크를 통해 재정의한 서비스 디자인협회의 정의를 참고 하도록 하며 그 내용은 다음과 같다. 고객이 서비스를 통해 경험하게 되는 모든 유- 무형의 요소(사람, 사물, 행동, 감성, 공간, 커뮤니케이션, 도식 등) 및 모든 경로(프로세스, 시스 템, 인터랙션, 감성로드맵 등)에 대해 고객 중심의 맥락적인 (contextual) 리서치 방법을 활용하여 이해관계자 간에 잠 재된 요구를 포착하고 이것을 창의적이고 다학제적 · 협력적 인 디자인 방법을 통해 실체화(embodiment)함으로써 고객 및 서비스 제공자에게 효과·효율적이며 매력적인 서비스 경험을 향상시키는 방법 및 분야를 의미한다. 위의 정의에서 밝힌 바와 같이 서비스 디자인에서 고객에게 더 나은 서비스 를 제공하기 위해서는 유용한 리서치 방법을 활용하여 프로 세스, 시스템, 인터렉션, 감성로드맵 등을 파악해야 한다. 그 러기 위해서는 특히 서비스 경험에서의 부정적인 감성 요소 를 포착하여 서비스 질을 향상시킬 수 있는 방법을 연구해 보도록 한다.

\subsection{The limitations of existing methods of service design}

서비스 경험 안에서의 감성 변화에 대한 필요성이 증대 되고 있으나 경험 디자인에 비해 서비스 디자인에서의 감성 연구는 미비한 수준이다. 그러므로 기존 조사 방법론에서 사용되고 있는 대표적인 방법론들의 감성적 측면으로의 한 계점을 분석하여 보완해야 할 부분을 파악하도록 한다. 본 논문에서는 대표적인 조사 방법론으로 비디오 에쓰노그라피 (Video Ethnography), 컬쳐 프로브(Cultural Probes), 인 뎁쓰 인터뷰(Indepth-inerview), 에모카드(Emocard), 고 객여정(Customer Journey)을 Table 1을 통해 살펴보도록 한다.

Table 1은 서비스 디자인의 주요 조사 방법론의 비교를 통해 감정적 측면에서 한계점을 발견할 수 있다. 첫 번째, 실제 리서치 단계마다 고객이 느끼는 내제된 감정 파악이 어 렵고 두 번째, 일반적으로 지나간 감정을 떠올리고 묘사하는 데 어려움이 있으며 세 번째, 리서치 상에서 발생되는 감정 변화를 충분히 포착할 수 있는 환경을 만들기 어렵다는 것이 다. 이 외에 기존 방법론이 가지는 한계점은 리서치 실행 후 데이터를 분석하기 위해 시간을 따로 써야 하며, 데이터 분 
Table 1. The result of comparison of existing methods

\begin{tabular}{|c|c|c|}
\hline Name & No. & Contents of comparison \\
\hline \multirow{5}{*}{$\begin{array}{l}\text { Video } \\
\text { ethnography }\end{array}$} & 1 & $\begin{array}{l}\text { There is psychological burden of the researcher } \\
\text { when analyzing the data after the research. }\end{array}$ \\
\hline & 2 & $\begin{array}{l}\text { Time is consumed in analyzing meaningless } \\
\text { data. }\end{array}$ \\
\hline & 3 & $\begin{array}{l}\text { There is lack of resolution for the questions } \\
\text { posed on what's happening in the situation. }\end{array}$ \\
\hline & 4 & $\begin{array}{l}\text { There is possibility in understanding what a } \\
\text { person is doing through observing his/her } \\
\text { behavior as well as sensing the emotions from } \\
\text { observing his/her facial expression. However, } \\
\text { there is difficulty in understanding the inner } \\
\text { emotions. }\end{array}$ \\
\hline & 5 & Research data analysis takes place afterwards. \\
\hline \multirow[b]{3}{*}{$\begin{array}{l}\text { In-depth } \\
\text { interview }\end{array}$} & 1 & $\begin{array}{l}\text { Due to the interviewers' subjective analysis, } \\
\text { wrong insight may be extracted. }\end{array}$ \\
\hline & 2 & $\begin{array}{l}\text { The interviewer is required a skill of posing } \\
\text { specific questions that clarifies eventual values. }\end{array}$ \\
\hline & 3 & $\begin{array}{l}\text { Difficulty of getting customers' emotional } \\
\text { response based on these following reasons: } \\
\text { 1) Limitations of customers' memory } \\
\text { 2) Nature of summarizing specific emotion in } \\
\text { each step } \\
\text { 3) Distortion and justification of emotions } \\
\text { 4) Limitations of expression }\end{array}$ \\
\hline \multirow{2}{*}{$\begin{array}{l}\text { Cultural } \\
\text { probe }\end{array}$} & 1 & $\begin{array}{l}\text { The main emotion in the research can be } \\
\text { ignored due to the subjective recording of } \\
\text { emotions of the customers. }\end{array}$ \\
\hline & 2 & $\begin{array}{l}\text { There are limitation to get customers' emotions, } \\
\text { therefore Video Ethnography method may be } \\
\text { used as well. }\end{array}$ \\
\hline \multirow[b]{2}{*}{ Emocard } & 1 & Actual emotions cannot be detected. \\
\hline & 2 & $\begin{array}{l}\text { Each customers may have different perspectives } \\
\text { on the emotions expressed on the cards. }\end{array}$ \\
\hline \multirow{3}{*}{$\begin{array}{l}\text { Customer } \\
\text { journey }\end{array}$} & 1 & $\begin{array}{l}\text { Similar to Culture Probe, there is characteristic } \\
\text { to understanding the emotions of a particular } \\
\text { situation. }\end{array}$ \\
\hline & 2 & $\begin{array}{l}\text { There is possibility of recording emotions from } \\
\text { repetitive experience, however there is possible } \\
\text { difficulty in capturing emotions from one time } \\
\text { experience. }\end{array}$ \\
\hline & 3 & $\begin{array}{l}\text { Due to the burden of the customers in recording } \\
\text { their emotions at each service step, the research } \\
\text { field may be unnatural compared to the actual } \\
\text { behavior. }\end{array}$ \\
\hline
\end{tabular}

석에 드는 의미 없는 시간이 발생하고, 제한된 관점을 통해 데이터를 분석함으로 제한된 인사이트를 추출하기가 쉽다는 한계점이 있다. 그러므로 위와 같은 한계를 극복할 수 있는 서비스 디자인 방법론이 필요하다.

\section{Limitations and Understanding of Service Design}

그렇다면 과연 감성이라는 주제를 서비스 디자인필드에서 연구해야 하는 이유는 무엇일까? 뇌 과학자 한스-게오르크 (2008)는 자신의 저서 '뇌, 욕망의 비밀을 풀다'에서 아래와 같이 밝혔다.

인간의 모든 결정의 70 80\%는 무의식적으로 내려지며 나머지 20 30 퍼센트 또한 우리가 생각하는 것만큼 자유롭 지 못하다. 고객의 뇌는 우리가 미처 알아차리지 못하는 사 이에 수많은 자극과 신호를 곧바로 행동으로 전환시킨다. 고 객이 내리는 모든 중요한 결정은 감성적이다. 감성적인 요소 가 개입되지 않은 결정은 고객의 뇌 속에서 아무런 의미를 갖지 못한다.

서비스 디자인에서 감성을 봐야 하는 이유는 인간은 자신 을 이성적이고 의식적으로 행동하는 인간으로 규정하여 스 스로를 의식적이고 합리적인 소비자라 생각하지만 뇌 연구 에 의하면 나의 '자아'가 의식적으로 결정한다고 여기는 것은 착각에 불과하다. 고객이 논리적인 판단으로 구매를 결정한 다고 생각하지만 그 기준이 사실은 감정이기 때문이다. 그러 므로 서비스 디자인 리서치에서 각 단계에서의 감성 변화를 포착하여 감정에 부정적인 영향을 끼치는 요소를 발견하여 긍정적인 요소로 바꿔줄 수 있도록 사용할 수 있는 방법론의 개발이 필요하다.

\subsection{The customer emotions in the area of service design}

이번 장에서는 새로운 서비스 조사 방법론의 제시를 위해 서비스 디자인에서의 감성의 성질을 정의하고 그 특성을 설 명하도록 한다. 먼저 감성의 성질에 대한 정의는 감성연구에 있어 서비스 디자인보다 앞서 연구되어온 타 분야에서의 감 성연구를 기반으로 설명하도록 하고 그 후에 감성의 성질이 가지는 특성을 설명하도록 한다.

서비스 디자인에서의 고객감성의 성질을 정의하기 위해서 는 순간의 사용자 경험, 감성의 순환, B3-감성시스템의 개 념들을 이해하는 것이 필요하다. 각각의 개념들을 이해하기 위해 아래에 설명하고 있는 3 가지 연구에 대해 먼저 살펴보 도록 한다.

\subsubsection{Understanding of MUX(Momentary User eX- perience)}

먼저 '순간의 사용자 경험'에 대해 살펴본다. '순간의 사용 자 경험'은 제품 사용 중 겪게 되는 세부적인 감성 변화를 의미한다. [Figure 1]은 사용자의 경험기간으로 사용자의 
경험기간은 예상되는 '사용자 경험(Anticipated UX)', '순간 의 사용자 경험(Momentary UX)', '에피소드 사용자 경험 (Episodic UX)', '누적되는 사용자 경험(Cumulative UX)' 의 4 단계로 이뤄진다.

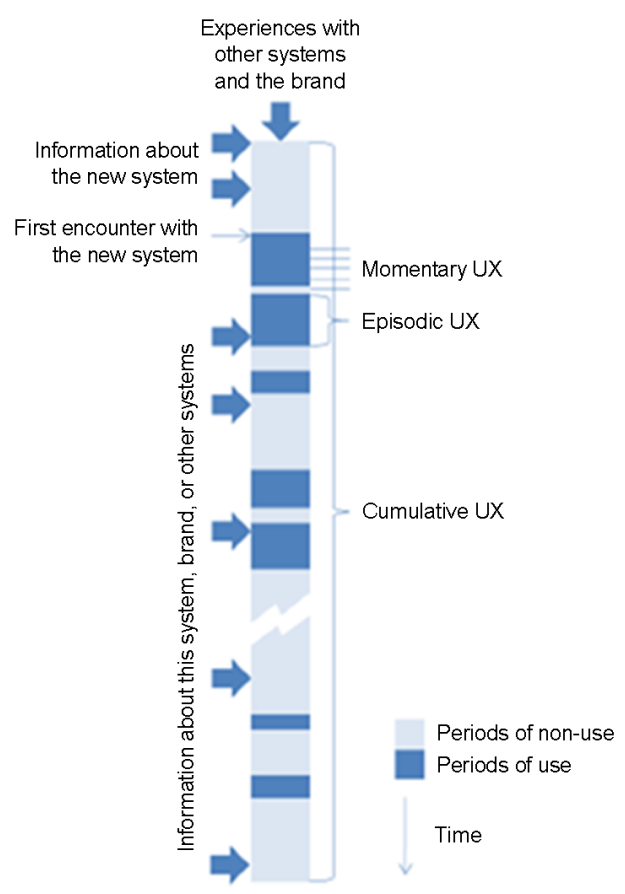

Figure 1. UX over time with period of use and non-use

이 중 서비스 디자인 리서치에서는 '순간의 사용자 경험' 의 단계를 개념을 반영해서 다루도록 한다.

서비스 디자인 경험은 고객이 순간마다 접촉하는 세부적 인 감정 변화 단계들의 집합으로 볼 수 있기 때문이다. 그러 므로 서비스 전체 경험 과정 중 각각의 순간마다 겪는 고객 의 세부적인 감정 변화를 '순간의 서비스 경험(Momentary Service eXperience)'라고 한다. Figure 2에서 보는 바와 같이 서비스 디자인은 이러한 '순간의 서비스 경험'의 집합이 라고 할 수 있다. 그렇다면 고객이 서비스 단계에서 처음 겪 는 '순간의 서비스 경험' 단계에서 다음 단계인 '순간의 서비 스 경험'으로 넘어갈 때는 어떤 일이 일어나는지 감정의 순 환 이해를 통해 살펴보도록 한다.

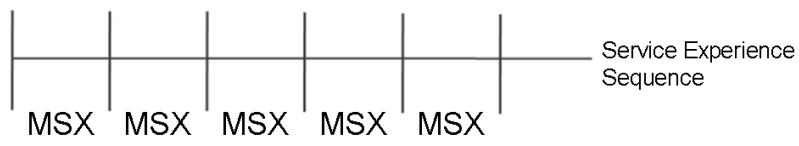

Figure 2. Service sequence is a set of MSX

\subsubsection{Understanding of circumflex of emotions}

Figure 3에서 제시하는 Core-affect는 Desmet이 Russell의 이론을 받아들인 것으로, 경험 디자인에서 경험에 대한 적절한 감성의 반응에 대해 나열한 것이다. 인간의 감 성은 Figure 3 과 같이 끊임없이 변화하며 한 축에서 다른 축으로 감성의 기복을 경험한다. 호르몬의 변화든 영양분의 부족이든, 이벤트나, 사람, 물건, 날씨에 의해 감성은 계속 변한다. 서비스 디자인을 경험하는 고객의 감성도 서비스 시 퀀스(sequence) 상에서 서비스 제공자의 태도, 표정, 등등 의 자극에 의해 순간적으로 변할 수 있다. 감성은 순환 고 리 상에서 특정 위치를 가지다가 자극(arousal)에 의해 그 위치가 바뀌게 되는데 이러한 감성의 변화를 감성의 순환 (Circumflex of Emotions)이라 한다(Russell 1980).

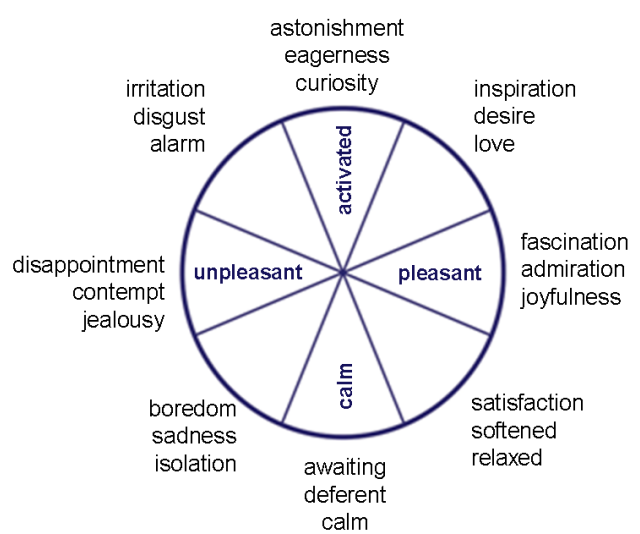

Figure 3. Core-affect of Desmet

Figure 4에서 보는 바와 같이 서비스 디자인에서 고객은 '순간의 서비스 경험' A 단계에서 다음 '순간의 서비스 경험' 인 B 단계로 이동할 때에 특정 자극(arousal)에 의해 감정 은 순환 과정(화살표)을 경험하게 된다. 예를 들어 식당에 들어간 순간(순간의 서비스 경험) 고객을 맞이하는 점원이 인상(arousal) 을 찌푸린다면 자리에 앉으면서(순간의 서비 스 경험) 식당에 진입했을 때와의 감정과는 다르게 변했을

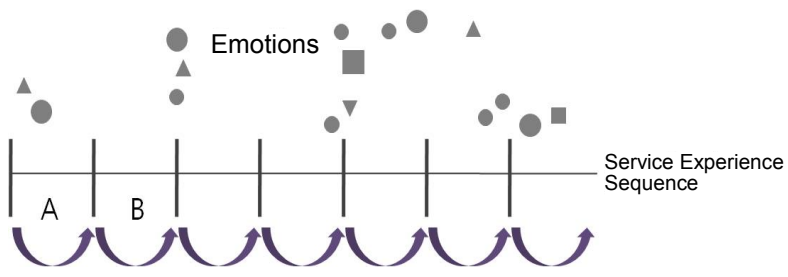

Figure 4. Circumflex of emotions occurs between MSX and MSX 
것이다(감정의 순환). 그러므로 리서치 현장에서 이 자극의 요소가 무엇인지 밝혀내는 것이 필요하다.

\subsubsection{Understanding of the Big-3 emotional system}

서비스 시퀀스에서 발생되는 감정은 자극(arousal)에 의 해 바뀐다는 특성 외에 각 단계에서 어떻게 작용할까? 그에 대한 답은 이번 장에서 설명하는 $\mathrm{Big}-3$ 감성시스템의 설명 을 통해 알아보도록 한다. 앞서 3장 서론부분에서 고객의 구 매결정은 거의 언제나 뇌에서 무의식 가운데 감성적으로 내 려지므로 인간의 모든 결정은 감성적이며 의식은 모두 합리 화할 뿐 이라는 것을 보았다. 고객이 결정을 할 때 'B3-감 성시스템'의 협력을 통해 이뤄지며 그 과정에서 이성은 전혀 찾아볼 수 없다. 이 시스템을 이루는 3 가지 요소는 균형시스 템과 지배시스템 및 자극시스템이다. 균형시스템은 우리 두 뇌에서 가장 막강한 힘을 행사하는 감성시스템으로 안전함 을 추구하고 위험을 회피하게 만듭니다. 지배시스템은 경쟁 자를 축출해 자신이 보다 우월한 존재로 부각되고 싶어 하 는 감성이다. 자극시스템은 지겨움과 불쾌감은 피하려고 하 고 즐거움과 짜릿함과 같이 기분전환을 할 수 있는 새로운 경험을 추구하는 행위와 관련된 것이다. 서비스 시퀀스 상에 서 고객은 각각의 '순간의 경험' 단계마다 결정을 내려야 하 는 상황(Decision Making)을 직면하게 된다. 그때 고객은 $\mathrm{Big}-3$ 감정시스템의 작동으로 감정적 결정을 내린다.

\subsection{Customers volatile emotions}

지금까지 3 가지의 개념을 토대로 '순간의 서비스 경험' (Momentary Service eXperience) 과 감성의 순환 및 B3감성시스템의 개념을 정의하였다. 이 세 가지를 통해서 고객 은 한 순간의 서비스 경험에서 다양한 감정을 느끼게 되고, 그 감정이 여러 가지 자극 요인에 따라 바뀌게 되어 감정의 순환을 경험한다는 것을 살펴보았다. 그리고 고객은 서비스 를 대하면서 중간마다 결정을 하게 되며 그 결정은 Big-3 감정시스템에 의한 감정적인 결정이라는 것을 설명하였다.

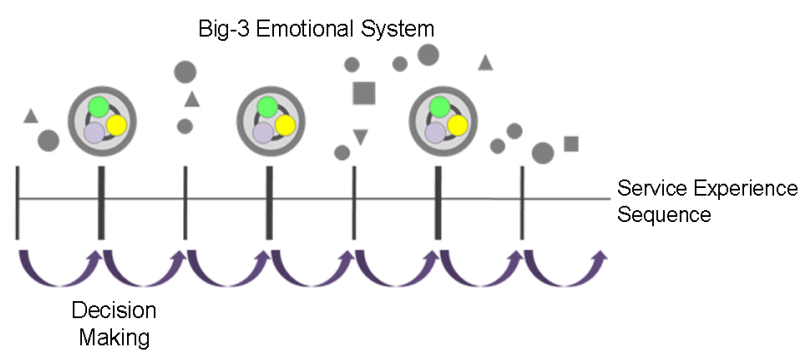

Figure 5. At the moment of decision that works in Big-3 emotional system
$\mathrm{BIg}-3$ 시스템은 Figure 5와 같으며 그림을 이루는 각각의 요소는 Figure 7 에서 설명한다.

따라서 이번 장에서는 서비스 각 단계에서 겪는 고객의 감 정이 휘발적인 성질로 존재한다는 것과 그 특징을 살펴보도 록 한다. 서비스 디자인 단계에서 고객이 경험하는 감성은 순간적으로 생겼다가 없어지기 때문에 휘발적(volatile)이다. Figure 6에서 보는 바와 같이 서비스 시퀀스에서 생기는 감 성은 자극(arousal) 요소에 의해 금방 다른 감성으로 변한 다. 또한 의사결정 시 판단 기준이 되는 감정은 순간적인 찰 나에 생겼다가 없어지므로 휘발적인 성질을 가지고 있다고 정의할 수 있다. 이러한 성질을 가지는 것이 고객감성이며 리서치에서 세세하게 다루는 것이 필요하다. 그렇다면 이러 한 휘발적인 고객감성이 가지는 특징은 무엇인지 살펴보도 록 한다.

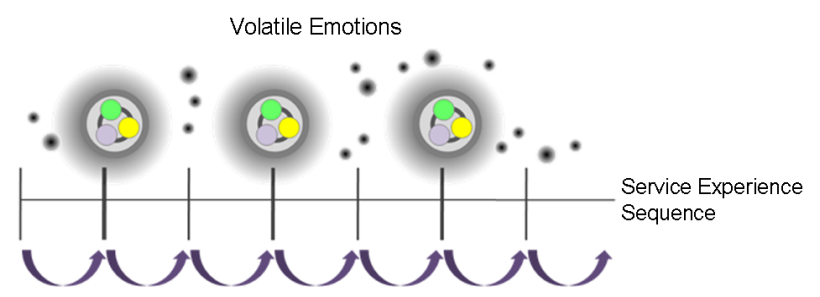

Figure 6. Volatile emotions that occur in the service sequence

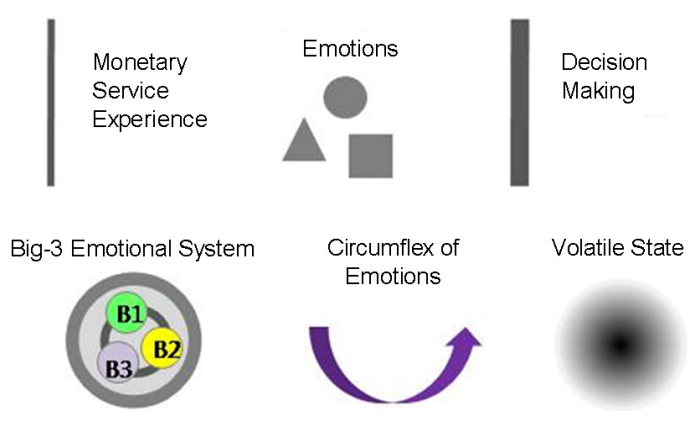

Figure 7. The elements of volatile emotions

\subsection{Characteristics of customer's volatile emotions}

(1) 불예측성 (unpredictability): 고객이 서비스를 경험하 는 기간 동안 중 어떤 시점에 감성이 변하게 되는지 예측 할 수 없다. 감성은 여러 가지 변수에 의해 갑자기 바뀌게 됨으로 변하는 시점을 대비할 수 없다. 서비스 각 시점 (Momentary Service eXperience) 에서 감성이 변하는 시 기는 서비스 환경마다 다르다.

(2) 소멸성(extinctive): 리서치에서 보이는 고객감성은 
소멸성을 가지고 있다. 순간적으로 생겼다가 순간적으로 사 라지는 속성을 가지고 있기 때문에 고객감성에 대한 정보를 수집하는 것 자체가 어렵다. 리서치가 끝난 후 고객에게 피 드백을 통해서 들을 수 있으나 고객은 전체 경험의 결과가 좋으면 부정적인 경험에 대해서도 긍정적으로 기억하거나 서비스 단계가 길 경우 서비스 경험에서 느낀 세부적인 감성 을 기억하지 못하므로 부정적인 요소를 발견하기가 어렵다.

(3) 가변성 (changeability): 감성은 자극에 의해 변하는 특성을 가진다. 인간은 끊임없이 감성의 기복을 경험한다. 호르몬의 변화든 영양분의 부족과 같은 내부적인 요소나 이 벤트나, 사람, 물건, 날씨와 같은 외부적인 요소에 의해 감성 은 계속 변한다. 고객감성이 변하게 되는 변수가 어떤 것인 지도 개인의 상태나, 취향, 성격에 따라 다른 반응을 하기 때문에 적절한 대응이라는 것이 어렵다. 이와 같이 휘발적인 감성이 불예측적이며 소멸적이고 가변적이므로 다면적인 접 근이 필요하다.

(4) 다면적인 접근(various aspects)필요: 휘발성을 가지 는 고객감성을 포착하기 위해서는 한 사람의 역량으로는 파 악하기가 어렵다. 리서치를 관찰하고 분석하는 사람은 개인 이 가진 경험에 의존하기 때문에 한 명의 관찰자의 주관적인 해석으로는 휘발적인 감성을 읽어내는데 어려움이 있다. 여 러 사람의 관점으로 파악해야 하는 휘발적인 감성의 특징은 다면적인 접근을 통해 관찰해야 한다.

기존 방법론을 통해서 고객의 니즈를 발견하기 위한 많은 노력을 해왔으나 리서치에서 발생되는 휘발적인 고객감성에 대한 충분한 정보는 얻기가 어려웠다. 휘발적인 감성은 언제 바뀔지 모르고, 순간적으로 생겼다가 순간적으로 없어지며, 여러 변수에 의해 변하고, 제한된 관점으로는 파악하기 어려 운 특징을 가지고 있기 때문이다. 다음 장에서는 위와 같은 특징을 가지는 휘발적인 감성을 포착하여 고객의 감성이면 에 내재된 고객 니즈를 추출하는데 효과적으로 사용하고 이 와 더불어 앞서 2장에서 설명한 기존 방법론의 한계점을 극 복할 수 있는 방법론인 SOMC 방법론을 제안한다.

\section{Definition and Structure of the SOMC}

\subsection{Definition of the SOMC}

SOMC 방법론 Simultaneous Observation Method based on Cooperation (이하 SOMC)은 현장에서 이뤄지는 서비스 경험을 전체적인 관점과 개인적인 관점을 통해 촬영하고 인
터넷 스트리밍 서비스 네트워크를 기반으로 생중계되는 영 상을 이해관계자들이 시청하며 실시간으로 활발한 인터렉션 을 통해 서비스의 각 단계에서 휘발성 있는 고객감성을 생생 하게 포착할 수 있는 방법론이다.

\subsection{SOMC methodological approach}

$\mathrm{SOMC}$ 는 크게 두 접근 방식으로 나뉘는데 전체를 조망 할 수 있는 TPA 접근법(Third-person Point of view Approach) 과 현장에서 일어날 수 있는 일을 면밀히 관찰할 수 있는 FPA 접근법(First-person point of view)은 한 현장에서 동시에 실행하는 방법론이다. 각각의 접근법에 대 한 세부설명은 다음과 같다.

(1) TPA 접근법 Figure 8-A와 같이 서비스 공간에서 일 어나는 일을 전지적 작가 시점인 전체조망을 통해 관찰을 한다. 전체를 볼 수 있는 곳에 카메라를 설치하여 서비스가 일어나는 현장의 경험과 감성 변화를 공간의 의미로 해석한 다. 주요 서비스가 일어나는 곳에 마이크를 설치하고 고객의 대화내용을 녹취하여 심리상태를 예측한다. 현장에서 일어나 는 일들과 대화 내용은 실시간으로 방송되며 서버를 통해 외 부에 있는 이해관계자들 (4.4참여자의 용어정의 참고)에게 전송된다. Figure 8-C에서 설명하듯이 이해관계자들이 각 각의 베이스캠프에서 네트워크로 연결되어 실시간으로 방송 을 관찰과 동시에 분석하면서 의견을 교환한다.

(2) $\mathrm{FPA}$ 접근법-고객이 서비스 제공을 받는 시점부터 각 세부 단계에서 일어나는 일련의 과정을 고객의 1 인칭 시점 을 통해 관찰한다. Figure 8-B에서 보는 바와 같이 카메라 와 컴퓨터 외 기본 장비를 갖춘 리서치 수행자와 리서처(이 하 동행자)가 함께 팀을 이뤄 서비스를 직접 경험하며 리서 치를 수행한다. 각 베이스캠프의 이해관계자(Stakeholder) 들이 인터넷 스트리밍 서비스를 통해 방송되는 리서치 수행 과정을 실시간으로 시청하며 현장에서 일어나는 일을 관찰 과 동시에 분석하며 의사소통 한다. 리서치 수행 중 이해관 계자들이 리서치 수행팀에게 감정적 변화를 비롯한 궁금한 사항이 생길 경우 컨트롤 타워에서 질문을 하여 실시간으로 답을 얻을 수 있다. 더 잦은 감정 변화를 발견할 수 있도록 리서치 과정을 반복하거나 설정방향을 바꿔서 진행해야 할 경우에도 컨트롤 타워에서 이해관계자들의 의견을 집결하여 리서치 수행팀에 지시하고 $\mathrm{FPA}$ 수행팀이 대응하도록 한다. 리서치가 진행되는데 방해가 되지 않는 범위 내에서 실시간 으로 질문을 할 수 있으며 방해가 될 경우 메모를 해두어 리 서치가 끝난 후 토의단계에서 물어본다. 


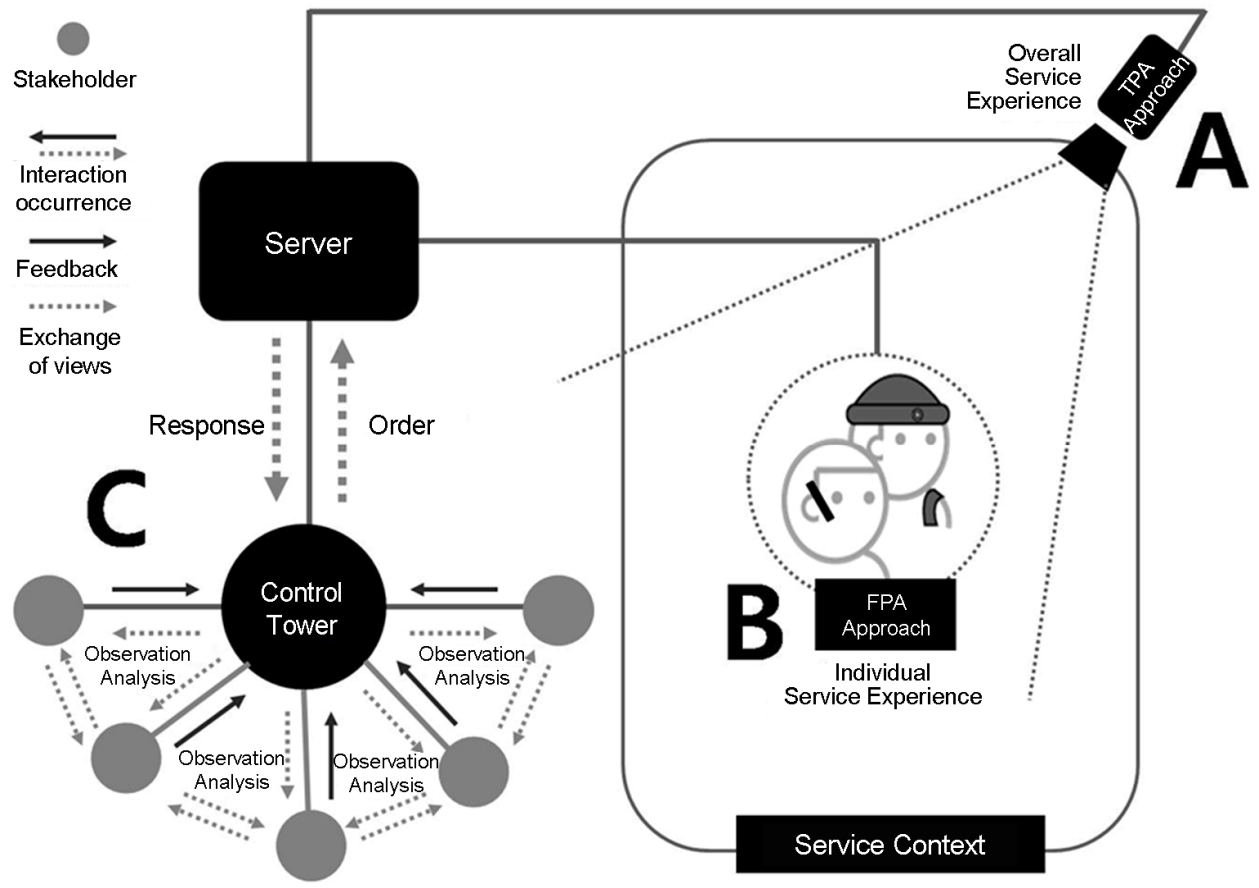

Figure 8. Structure of the SOMC

\subsection{The main features of the SOMC methodology identity compared with conventional methods}

(1) 고객을 최대한의 감성을 경험할 수 있는 상황에 노출 시켜 휘발성 있는 감성을 잡을 수 있도록 한다.

$\mathrm{SOMC}$ 방법은 이전 방법과 비교했을 때 보다 감성에 집 중하고 있어서 감성을 충분히 끄집어 낼 수 있는 환경을 만 들어 줄 수 있다는 특징이 있다. 감성이 일어날 수 있는 상 황을 만들어서 감성이 일어나는 포인트 발견을 통해 최대한 감성을 많이 찾아 낼 수 있게 하는 방법론이다. Figure 8에 서 보는 바와 같이 중간에 리서치 수행팀과의 원활한 인터 렉션을 통해 중요하다고 생각되는 감정은 그 단계를 다시 반복하게 하거나 또는 변경할 수 있게 하여 새로운 감정로드 맵을 밟을 수 있다는 장점이 있다.

\section{(2) 실시간 인터렉션을 통해 감정이입이 가능하다.}

Figure 6와 같이 TPA 수행 카메라와 FPA 리서치 수행 팀의 모습이 서버를 통해 실시간으로 중계되는 영상을 이해 관계자들이 보면서 리서치 현장에서의 고객감정에 충실이 이입이 되므로 고객의 감정 포인트의 발견이 쉽다. 대부분의 기존 방법론들은 리서치가 끝난 후에 데이터를 분석하기 때 문에 실제 현장에서 일어나는 일을 그대로 체감하는 것이 어 렵다. 그에 반해 SOMC 방법론은 실시간으로 일어나는 일을 관찰하면서 고객의 시선(FAP 접근법)으로 촬영되는 화면을
보기 때문에 감정적인 몰입이 강하다는 장점이 있다.

(3) 협력체제를 통한 다각적 관점(Many-sided Perspective)으로 판단을 용이하게 한다.

Figure 8-C와 같이 이해관계자들이 실시간으로 협력하여 관찰하므로 감성이 어디서 변하는지 감성의 변화 포착에 유 용한 방법론이다. 사람마다 감성을 느끼는 부분이 각각 달라 이입이 안 되는 부분도 생기지만 공동작업(collaboration) 을 통한 이해관계자간의 의견교환으로 좀 더 객관화된 감성 을 측정할 수 있다.

(4) 관찰자(이해관계자)가 1 인칭 시점이면서 전지적 시 점을 동시에 가진다.

이해관계자들이 중계되는 영상을 관찰할 때 보이는 영상 은 1 인칭 시점과 전지적 시점을 동시에 관찰할 수 있으므로 전체적인 관점과 개인적인 관점을 동시에 가질 수 있다는 장 점이 있다. 각 시점에 따라 보이는 것이 다르기 때문에 한 가지 현상에 대한 다각도의 관점으로 관찰이 가능하다.

(5) 정황상 전체적인 흐름에서 어떤 단계에 변화가 있을 것이라고 예측하는 것이 가능하다.

$\mathrm{SOMC}$ 방법론으로 서비스 경험의 단계에서 모든 휘발적 인 감성을 다 포착할 수 있는 건 아니다. 다만 감성의 포인 트가 어딘지를 각 단계에서 가정 (assumption)할 수 있다. 
분명하게 드러나는 행위나 표현으로도 드러나지 않는 내제 된 감성은 정황상 전체적인 흐름에서 어떤 단계에 변화가 있을 것이라고 예측하는 것이 가능하다. 그러므로 경험에 대 한 방향의 흐름을 잡을 수 있다.

(6) 네트워크(Network) 기반의 다방향 접속 지원 방식으 로 관찰과 분석의 동시진행을 통해 프로세스가 단축된다.

리서치를 수행한 후 리서치 데이터를 가지고 분석하는데 따로 시간을 들여야 하는 기존 방법론과는 달리 관찰과 동시 에 분석하는 것이 큰 장점이다. 리서치가 한 공간에만 이뤄 지지만 여러 명이 동시에 리서치 현장에 대한 정보공유가 가능한 네트워크기반의 방법론이다. 인터넷 스트리밍을 통해 실시간으로 인사이트를 추출하기 때문에 분석 시간을 따로 쓸 필요가 없다.

\subsection{SOMC process}

SOMCC 방법론의 프로세스는 Figure 9와 같이 크게 준 비 단계, 설치 단계, 실행 단계, 토의 단계의 4 가지 단계를 거치며 각 단계에서 세부적인 단계로 나눠진다.

\subsubsection{Preparation phase}

준비 단계는 Figure 8-A에서 보는 바와 같이 페르소나 선정, 리서치 수행자 섭외, 리서치 Too-Kit 준비 단계, 장 소 선정 및 섭외의 4 가지 세부 단계로 나뉜다.

(1) 페르소나 선정: 프로젝트 특성에 맞혀 기준을 정하여 유형을 선정하도록 한다.

(2) 리서치 수행자 섭외: 리서치에 적합한 페르소나를 섭 외를 하도록 한다.

(3) 리서치 Too-Kit 준비: TPA 접근법 Tool-Kit: 웹 캠, 컴퓨터, 전체를 조망할 수 있는 장치(예: 광각렌즈)가 필 요하다. 윕캠은 전체 내부촬영 시 더 넓은 시야확보를 위해 화각의 범위가 넓고 촬영되는 피사체의 유효한 확인을 위해 해상도가 높은 것을 사용하도록 한다. 컴퓨터는 데스크탑을 연결해도 무방하나 이동성을 고려하도록 하며 저장용량이 크고 장시간 영상 레코딩에 무리가 없는 것으로 준비한다.

FPA 접근법 Tool-Kit: 웹캠, 컴퓨터(인터넷 스트리밍 서 비스가 연결되어 있을 것) 백팩, 인스톨레이션 툴(Installation Tool) 준비하도록 한다. 인스톨레이션은 시야확보가 가능한 곳에 웹캠을 설치할 수 있는 것으로 준비하도록 하며, 이외에 컴퓨터선의 연결이 보이지 않도록 소품을 활용하도록 한다.

(4) 장소 선정 및 섭외: 클라이언트(Client)와 사전 이야 기를 통해 리서치에 합당한 장소를 선정하고 섭외하도록 한 다. 사람들이 너무 북적대는 시간은 영업에 방해가 되므로 피하도록 하며 웹캠으로 시야를 확보할 수 있는 면적의 장소
를 섭외하도록 한다.

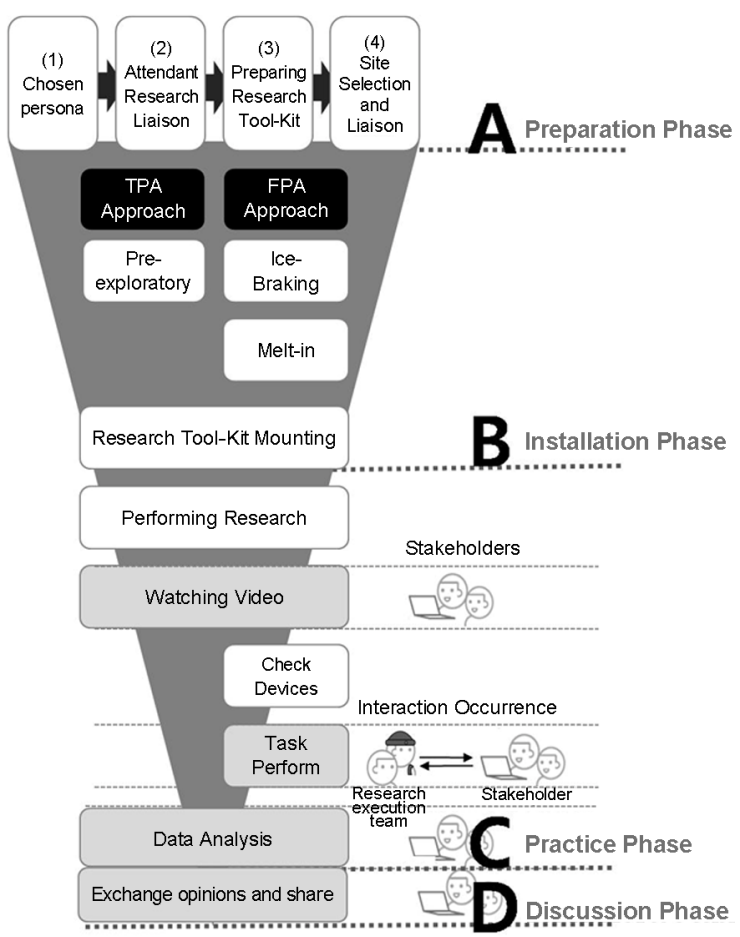

Figure 9. Process of SOMC

\subsubsection{Installation phase}

설치 단계는 Figure 8-B에서 보는 바와 같이 $\mathrm{FPA}$ 접근 법과 TPA 접근법의 실행 전에 하도록 한다. 진행하는 팀을 각 접근법에 따라 두 팀으로 나눠 준비하도록 한다.

\section{TPA 접근법의 설치 단계}

(1) 사전답사: 섭외된 장소에 사전답사를 통해 시행착오 를 줄이도록 한다. 필요한 물품과 필요장비를 다시 한 번 확 인하고 준비 물품이 실제 장소에 적합한지 여부와 설치 장소 를 탐색한다.

(2) TPA 접근법 Tool-Kit 설치: 전체조망 카메라를 설 치할 때 조망권을 확보할 수 있는 곳에 설치하도록 한다. 서비스가 활발하게 일어나는 장소에 마이크를 설치한다.

(3) Tool-Kit 장착 세부절차

이 단계는 다음과 같이 이뤄지며 Figure 10을 통해 참고 하도록 한다.

전체조망 설치 장소와 부분조망 설치 장소에 윕캠 설치하 기-> 웹캠을 컴퓨터와 연결하기 컴퓨터 켜기 $->$ 웹캠 설 치하기 $->$ 인터넷 스트리밍 서비스 연결 $->$ 채널방 만들기 $->$ 이해관계자들 채널방 접속-> 대기 


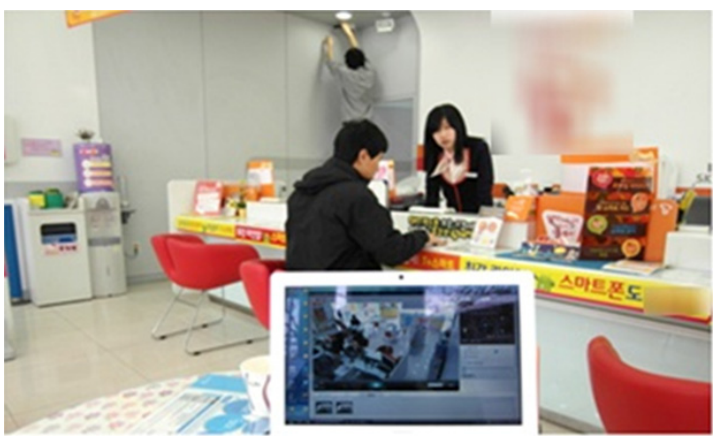

Figure 10. Example pictures of TPA approach tool-kit installation

\section{FPA 접근법의 설치 단계}

(1) 아이스 브레이킹과 Melt-in: 리서치 수행에 앞서 주요 수행 요점과 실시사항에 대해 알려주어 리서치 수행에 필요한 사항을 공유한다.

(2) FPA 접근법 Tool-Kit 장착 세부절차: 리서치 ToolKit 장착은 동행자와 수행자 둘 중 하나가 장치를 착용하도 록 한다. 장치 장착에 앞서 다시 한 번 장치가 제대로 작동 하는지 확인해야 한다(예시: 노트북 배터리 용량을 확인하여 리서치 수행 시간 동안 컴퓨터가 꺼지지 않도록 하며 수면 모드로 되어 있을 경우 해제시켜 주도록 한다).

(3) FPA 세부절차

이 단계는 다음과 같이 이뤄지며 Figure 11을 통해 참고 하도록 한다. 웹캠을 인스톨레이션에 장착한다-> 컴퓨터 켜 기-> 웹캠과 컴퓨터 연결하기 $->$ 인터넷 스트리밍 서비스 접속-> 채널방 만들기 $->$ 이해관계자들 채널방 접속-> 대 기-> 웹캠이 장착된 인스톨레이션 착용하기-> 컴퓨터 백 팩에 넣기-> 4. 장착한 Tool-Kit을 소품을 활용해 가리기

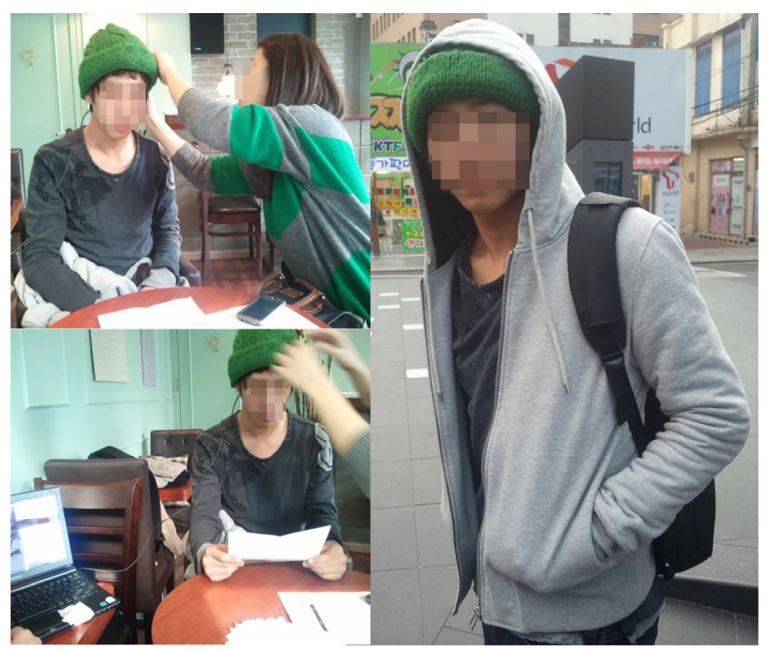

Figure 11. Example pictures of FPA approach tool-kit installation

\subsubsection{Practice phase}

설치 단계가 끝나면 Figure 9-C와 같이 리서치 수행 단 계로 들어간다. 리서치 수행자들이 리서치를 수행하는 동안 컨트롤 타워 (Control Tower) 에 있는 이해관계자들은 TPA 접근법과 $\mathrm{FPA}$ 접근법으로 출력되는 영상을 보며 두 개의 영상채널을 켜두고 관찰을 한다. 영상을 보며 이해관계자간 에 이슈를 공유하고 분석할 수 있다. 특별히 $\mathrm{FPA}$ 접근법이 실행되는 동안 지시상황을 통해 Task를 받을 수 있다. 각 접근법에 따른 실행 단계를 구체적으로 설명한다.

\section{TPA 접근법의 실행 단계}

(1) 리서치 수행: TPA팀은 설치가 끝나면 구매하는 사람 들에게 방해가 안 되는 장소에서 촬영영상을 보면서 이해관 계자들과 대화창을 통해 소통한다.

(2) 영상시청: 이해관계자들이 개입하는 부분이다. 이해관 계자들이 각자가 위치한 곳에서 채널에 접속하여 관찰하도 록 한다. 영상을 보며 대화가 가능하기 때문에 이해관계자간 에 발견되는 이슈들을 이야기하거나 고객들의 움직임에 대 해 궁금한 상황은 리서치 현장에 있는 설치팀(Researcher) 에게 질문하도록 한다. 촬영되는 영상은 리서치 실행 후 필 요 시 확인할 수 있게 녹화하도록 한다.

(3) 실시간 기기점검: 설치팀은 리서치가 진행되는 동안 수시로 기기를 점검하면서 대기한다. 만약에 생길 기계적인 결합문제를 대비하도록 한다.

(4) 의견교환 및 공유: 리서치가 끝난 후 설치팀은 리서치 베이스팀에 합류하여 컨퍼펀스 콜을 통해 이해관계자들과 의견을 교환하며 공유하도록 한다.

\section{$\mathrm{FPA}$ 접근법의 실행 단계}

1) 리서치 수행: 리서치 수행자는 성향에 따라 소극적으 로 반응할 수 있으므로 동행자가 수행자를 격려해주도록 하 며 적극적으로 반응하는 것이 어려울 경우 상황을 리드해주 도록 한다. 리서치 수행 중 인스톨레이션에 달린 카메라가 서비스 제공자의 눈에 띄지 않도록 시선을 피하여 유연하게 대처한다.

2) 영상시청: 리서치가 실행되는 동안 리서치 수행자는 표정과 목소리, 행동으로 나타나는 고객의 휘발적인 감성 변 화를 포착하는데 집중하도록 한다.

3) 실시간 기기점검: 리서치 소품에 장착된 카메라는 수 행자의 미세한 움직임에도 위치가 변경될 수 있음으로 리서 치 동행자와의 인터렉션 채널(예: 핸드폰)을 통해 카메라를 조심스럽게 옮기도록 하여 촬영이 잘 진행될 수 있도록 한다.

4) Task 수행: 이해관계자와 적극적인 인터렉션이 일어나 는 부분이다. 리서치가 이뤄지는 동안 수행자는 인터렉션 채 
널을 통해 베이스캠프에 있는 리서치 수행팀의 이해관계자 나 다른 이해관계자들이 주는 Task를 받을 때 자연스럽게 리서치 수행자를 유도하도록 하며 특히 서비스 수행자에게 어색한 모습을 보이지 않도록 유념한다.

5) 데이터 분석: 이해관계들은 리서치 수행팀이 리서치를 수행하는 동안 발견되는 주요 사항과 고객감성을 포착하여 데이터를 즉시 분석하도록 한다. 서비스 단계에서 발생되는 다양한 휘발적인 감성에 대해 충분히 끄집어 낼 수 있는 상 황을 만들도록 하며 필요한 Task를 지시하고 리서치 수행 팀에게 방해가 되지 않는 한도 내에서 질문을 하도록 한다. 상황에 따라 인터뷰가 추가로 필요할 경우 따로 기록을 해두 어 리서치가 끝난 후 '의견교환 및 공유 단계'에서 질문하도 록 한다.

\subsubsection{Discussion phase}

리서치가 끝나면 Figure 9-D와 같이 리서치 수행팀이 컨 트롤 타워(Control Tower)에 합류하고 각 베이스 있는 이 해관계자들과 컨퍼런스 콜을 통해 의견을 나누고 질의응답 을 하는 시간을 가진다. 이때 리서치 수행 중 리서치 수행자 의 행동이나 감성에 대한 궁금한 부분을 기록해둔 상항에 대 해 질문하도록 한다.

\section{Conclusion}

먼저 $\mathrm{SOMC}$ 라는 이해관계자 협력체제의 동시관찰 서비스 방법론을 제안(1장)하기 위해 기존의 대표적인 서비스 디자 인 조사 방법론의 감성적인 한계를 분석 (2장)하였다. 그 후 경험 디자인과 뇌과학의 타 분야의 감성연구를 중심으로 서 비스 디자인에서의 휘발적인 감성을 정의하고 그 특성을 파 악하였다(3장). 그리고 이를 기반으로 휘발적인 감성을 포착 하기에 유용한 $\mathrm{SOMC}$ 방법론의 정의 및 구성, 프로세스와 주요특징을 규명 (4장)하였다.

$\mathrm{SOMC}$ 의 연구 내용을 기반으로 앞으로 서비스 디자인 리 서치에서 휘발성있는 고객의 감성을 파악하는데 효과적인 방법론으로 사용할 수 있을 것이라 기대한다. 이와 더불어 $\mathrm{SOMC}$ 방법론의 연구를 통해 기존의 서비스 디자인에서 미 비하게 다뤄졌던 감성연구에 미약한 보탬이 될 수 있을 것이 라고 생각한다. 추후 여러 프로젝트에 $\mathrm{SOMC}$ 를 활용함으로 써 추가적으로 발견될 수 있는 이점이나 고려사항을 파악해 볼 필요가 있다. 가능하다면 이러한 점들을 정량적인 데이터 로 수집함으로써 객관적인 검증 과정을 진행하여 객관성을 검증할 필요가 있다. 또한 리서치 실행 시 발견되는 데이터 에 대한 효율적인 분석 툴이 연구된다면 SOMC 방법론이 더 효과적으로 쓰일 수 있을 것으로 예상된다.

\section{References}

Desmet, Pieter., Overbeeke, Kees. and Tax, Stefan., Designing products with added emotional value; development and application of an approach for research through design. The Design Journal, 4(1), 2001.

http://servicedesign.or.kr/sub3.asp?pageNum=3\&subNum=1\&scrID=0000 000077.

Marc Hassenzah. 1 The Thing and I: Understanding the Relationship Between User and Product. Funology: Human-Computer Interaction Series, 3(1), 2005.

Peer Insight. Seizing the White Space: Innovative Service Concepts in the United States. 205, Helsinki: Tekes, 2007.

Pieter, Desmet. and Paul, Hekkert., Framework of Product Experience. international Journal of design, 1(1), 2007.

Stickdorn, M. \& Schneider, J., This is Service Design Thinking. BasicsTools-Cases. Amsterdam: BIS Publishers, 2010.

Virpi Roto, Effie Lawb, Arnold Vermeeren, Jettie Hoonhout. User experience white paper. Dagstuhl Seminar. 1(1), 2010.09.18., http:// www.allaboutux.org/uxwhitepaper

www.enginiegoup.co.uk

www.livework.co.uk

www.peerinsight.com

www.service-design-network.org

www.servicedesign.org

www.Thinisservicedesignthinkg.com/@This_is_SDT/\#tisdt

\section{Author listings}

Mi Young Seo: creatormia@gmail.com

Highest degree: Master degree, Department of Culture and Media Design, Handong Global University

Position title: Researcher, Life Experience Design Research Institute

Areas of interest: User Experience Design, Service Design

Eun Jong Lee: sbell@handong.edu

Highest degree: PhD Candidate, Department of Industrial Design, KAIST Position title: Professor, Department of Industrial Information Design, Handong Global University

Areas of interest: User Experience Design, Service Design, HCI

Date Received : 2012-01-05

Date Revised :2012-01-16

Date Accepted : 2012-01-19 